\title{
Co-prescription of opioids with benzodiazepine and other co-medications among opioid users: differential in opioid doses
}

This article was published in the following Dove Press journal: Journal of Pain Research

25 January 2017

Number of times this article has been viewed

\author{
Che Suraya Zin \\ Fadhilah Ismail \\ Kulliyyah of Pharmacy, International \\ Islamic University Malaysia, Bandar \\ Indera Mahkota, Kuantan, Pahang, \\ Malaysia
}

Purpose: This study investigated the patterns of opioid co-prescription with benzodiazepine and other concomitant medications among opioid users. Opioid dose in each type of co-prescription was also examined.

Patients and methods: This cross-sectional study was conducted among opioid users receiving concomitant medications at an outpatient tertiary hospital setting in Malaysia. Opioid prescriptions (morphine, fentanyl, oxycodone, dihydrocodeine and tramadol) that were co-prescribed with other medications (opioid + benzodiazepines, opioid + antidepressants, opioid + anticonvulsants, opioid + antipsychotics and opioid + hypnotics) dispensed from January 2013 to December 2014 were identified. The number of patients, number of co-prescriptions and the individual mean opioid daily dose in each type of co-prescription were calculated.

Results: A total of 276 patients receiving 1059 co-prescription opioids with benzodiazepine and other co-medications were identified during the study period. Of these, $12.3 \%$ of patients received co-prescriptions of opioid + benzodiazepine, $19.3 \%$ received opioid + anticonvulsant, $6.3 \%$ received opioid + antidepressant and $10.9 \%$ received other co-prescriptions, including antipsychotics and hypnotics. The individual mean opioid dose was $<100 \mathrm{mg} / \mathrm{d}$ of morphine equivalents in all types of co-prescriptions, and the dose ranged from 31 to $66 \mathrm{mg} / \mathrm{d}$ in the coprescriptions of opioid + benzodiazepine.

Conclusion: Among the opioid users receiving concomitant medications, the co-prescriptions of opioid with benzodiazepine were prescribed to $12.3 \%$ of patients, and the individual opioid dose in this co-prescription was moderate. Other co-medications were also commonly used, and their opioid doses were within the recommended dose. Future studies are warranted to evaluate the adverse effect and clinical outcomes of the co-medications particularly in long-term opioid users with chronic non-cancer pain.

Keywords: co-prescription, opioid, benzodiazepine, co-medication, opioid users, pain

\section{Introduction}

Patients with chronic pain are commonly associated with comorbidities and multiple mental disorders that include anxiety, depression, insomnia and substance abuse. ${ }^{1,2}$ In these patients, pain relief is not the only desired treatment outcome, but it also includes mood improvement, sleep and quality of life, all of which require co-prescription of opioids with other medications such as antidepressants, anticonvulsants, antipsychotics and sedative-hypnotics.

Antidepressants (e.g., venlafaxine and duloxetine) and anticonvulsants (e.g., pregabalin and gabapentin) are the adjuvant analgesics that had been found to be
Correspondence: Che Suraya Zin Kulliyyah of Pharmacy, International Islamic University Malaysia, Kuantan Campus, Jalan Sultan Ahmad Shah, Bandar Indera Mahkota, 25200 Kuantan, Pahang, Malaysia

Tel +6095704909

Fax+60957I6775

Email chesuraya@iium.edu.my 
beneficial and are recommended as the first-line treatment of neuropathic pain. ${ }^{3}$ Antipsychotics (e.g., quetiapine and olanzapine) are indicated in the management of major depressive disorders with psychotic features as an adjunct to antidepressants and short-term benzodiazepines. ${ }^{4}$ Their usage as adjuvant analgesics in the treatment of painful conditions is inconclusive due to mixed results and small sample size reported from previous studies. ${ }^{5}$ Sedative-hypnotics, particularly benzodiazepines, have shown a potential role in acute pain, but there is limited evidence to support the general use of benzodiazepines in chronic pain. ${ }^{6}$ In anxiety disorders, benzodiazepines (e.g., alprazolam and clonazepam) are the second-line therapy after patients are unable to tolerate antidepressants but are limited to short-term use of 2-4 weeks. There is no beneficial effect for long-term use of benzodiazepines. ${ }^{6}$

Although co-prescriptions of opioid with other medications may assist in the management of chronic pain, certain co-prescribing patterns increase potential harm and are associated with high risk of drug interactions and adverse events. ${ }^{7}$ A report from the US demonstrated that the rate of death from opioid overdose has quadrupled in the last 15 years, ${ }^{8}$ and the most common additional agents found among the opioid overdose death were benzodiazepines, followed by antidepressants, anticonvulsants and antipsychotics. ${ }^{9}$

Benzodiazepines, apart from being the main additional agent in the opioid overdose death, were also associated with increased rates of sedation, respiratory depression, cognitive dysfunction and sleep apnea. ${ }^{10-12}$ Patients who were co-prescribed opioids and benzodiazepines for chronic pain were also reported to be prescribed with a high dose of opioid for long term. ${ }^{13,14}$ This increases the risk of opioid overdose, specifically with opioid doses of $>100 \mathrm{mg}$ morphine equivalents per day. ${ }^{15}$ The practice of combining benzodiazepines and opioid analgesics has been recognized as both ubiquitous and substantial. ${ }^{16,17}$ The extent to which clinicians have cautioned patients against the concurrent use of benzodiazepines and opiates is unclear, but their co-prescribing presents a serious safety concern and is not well characterized.

Given these uncertainties, this study was prompted to address the patterns of opioid co-prescribing with benzodiazepine and other co-medications among opioid users. The daily opioid dose per patient in each type of opioid co-prescribing was also examined. We believe that this study will be an important first step to better understand opioid co-prescribing at an outpatient tertiary hospital setting in Malaysia and will help to improve the safety of opioid prescribing.

\section{Patients and methods Study design and data source}

This retrospective, cross-sectional study was conducted at an outpatient tertiary hospital setting in Malaysia after being granted the ethical approval by the Ministry of Health Medical Research Ethical Committee (MREC), Malaysia. Consent from patients was not required by the MREC as there was no direct patient involvement in this study. The outpatient department consists of various clinics such as pain clinic, medical clinic, surgical clinic, otorhinolaryngology clinic and palliative care clinic, and patients came in regularly for consultations at these clinics. Prescriptions for opioids (dihydrocodeine, tramadol, fentanyl, oxycodone and morphine) that were co-prescribed with other opioids/medications (benzodiazepines, antidepressants, anticonvulsants, antipsychotics and hypnotics) issued from January 2013 to December 2014 were reviewed.

Benzodiazepines included alprazolam, diazepam, clonazepam, lorazepam and midazolam. Gabapentin, sodium valproate, phenytoin, pregabalin, carbamazepine and levetiracetam were the anticonvulsants included in the study. Antidepressants included amitriptyline, sertraline, escitalopram, duloxetine, venlafaxine, agomelatine and mirtazapine. Antipsychotics included quetiapine, risperidone, haloperidol, olanzapine, chlorpromazine and clozapine. Zolpidem was the benzodiazepine-related hypnotic included in the study.

Co-prescription was based on the same-day prescription or within 45 days from the issuance date of subsequent prescription of opioid or co-medication. The identified co-prescriptions were stratified according to combination 2 (opioid + one co-medication) and combination 3 (opioid + two co-medications or more), and they were further stratified according to the type of co-prescription (Table 1).

Data from the prescription records included name of drug and dose, frequency, duration, quantity of supply, diagnosis and patient's demographics. The patients included in the study were those aged $>18$ years or older and who were receiving co-prescription opioids with other medications as mentioned earlier. The calculation of patients' ages was based on the date of the first prescription included in the study because patients might have multiple opioid prescriptions during the 2-year study period (2013 and 2014) where age increased with increasing year. The age was further stratified into five categories as follows: <40, 41-50, 51-65, 66-80 
Table I Details of opioid combinations and the most common drugs used in each combination

\begin{tabular}{|c|c|c|c|}
\hline Category & Combination & Details of combination & Most common drugs used in each combination \\
\hline \multirow[t]{5}{*}{ Combination 2} & $O P+O P$ & Opioid + opioid & Morphine + oxycodone \\
\hline & $O P+B Z D$ & Opioid + benzodiazepine & Tramadol + alprazolam \\
\hline & $O P+A C$ & Opioid + anticonvulsant & Oxycodone + gabapentin \\
\hline & $O P+A D$ & Opioid + antidepressant & Oxycodone/morphine/fentanyl + amitriptyline \\
\hline & Others 2 & Opioid + hypnotics or opioid + antipsychotic & Tramadol + zolpidem + haloperidol \\
\hline \multirow[t]{5}{*}{ Combination 3} & $O P+B Z D+A C$ & Opioid + benzodiazepine + anticonvulsant & Tramadol + alprazolam + sodium valproate \\
\hline & $O P+B Z D+A D$ & Opioid + benzodiazepine + antidepressant & Tramadol + alprazolam + sertraline \\
\hline & $O P+A C+A D$ & Opioid + anticonvulsant + antidepressant & Tramadol/fentanyl + gabapentin + amitriptyline \\
\hline & Others 3 & $\begin{array}{l}\text { Opioid + benzodiazepine + hypnotics or } \\
\text { opioid + benzodiazepine + antipsychotics or } \\
\text { opioid + anticonvulsant }+ \text { hypnotics or opioid } \\
+ \text { antidepressant }+ \text { hypnotics or opioid }+ \\
\text { anticonvulsant + antipsychotics or opioid + } \\
\text { antipsychotics + hypnotics }\end{array}$ & Tramadol + zolpidem + olanzapine + alprazolam \\
\hline & Others $>3$ & Others $>3$ (more than three drugs combination) & $\begin{array}{l}\text { Tramadol + alprazolam + quetiapine + sodium } \\
\text { valproate }\end{array}$ \\
\hline
\end{tabular}

Abbreviations: OP, opioid; BZD, benzodiazepine; AC, anticonvulsant; AD, antidepressant.

and $>80$ years. This study did not stratify opioid users into cancer or non-cancer because this was the first step to start in addressing the practice of co-prescribing among opioid users in Malaysia. As such, the information on the overall coprescribing patterns regardless of groups is useful. Moreover, the potential side effects and the drug interactions from the concurrent use are similar in all patients.

This study excluded the prescriptions for a suppository or parenteral opioid due to lack of conversion factors. Prescriptions for methadone, which is exclusively used for the treatment of opioid dependence, were also excluded. Nonsteroidal anti-inflammatory drugs (NSAIDs) and paracetamol were commonly prescribed in all types of combinations, and they were not stratified in a separate group. The highest proportion of co-prescriptions of opioid with NSAIDs was in the opioid + opioid combination ( $50 \%$ of this combination consists of opioid + NSAID combination).

\section{Opioid use}

The duration of opioid supply was calculated by dividing the quantity by the frequency (number of daily dose) of opioid for each prescription. The total days of opioid supply were calculated by summing across all co-prescriptions for each patient during the study period. The overlapping day supply between opioid co-prescriptions was subtracted because we assumed that the first prescription was completed before the second prescription was started rather than assuming that a higher amount of drug was taken during the overlap. The overlapping days were only included once in the calculation of opioid day supply. ${ }^{18,19}$
The quantity of each opioid prescription was multiplied by the strength in milligrams of opioid per unit dispensed of the prescription to derive the total morphine equivalents for each opioid in the co-prescription. The milligram of morphine equivalent of the prescription was calculated by multiplying the quantity-strength with the equianalgesic ratio of the opioid. ${ }^{20,21}$

The total opioid dose was calculated by summing the opioid dose across all co-prescriptions for each patient during the study period. The total opioid dose was then divided by the total number of days supplied with opioid to derive the mean opioid dose per day in morphine equivalents for each patient in each type of combination during the study period. ${ }^{22-25}$ Prescriptions with extreme values of average individual daily dose of $>1000 \mathrm{mg}$ morphine equivalents $(0.5 \%)$ were excluded from the analysis in order to protect against data entry error, and morphine equivalents were conservatively estimated using this approach. ${ }^{26}$

\section{Data analysis}

The outcome measures included number of patients and number of co-prescriptions. The most common type of opioid and co-medication used in each combination and the mean daily opioid dose per patient in each combination were also calculated. Descriptive statistics such as mean and proportion were used to report the outcome variables including the number of patients and co-prescriptions and the mean daily opioid dose per patient. All analyses were performed using Stata 13 (Stata Corp LP, College Station, TX, USA, 2011). 


\section{Results}

\section{Number of patients}

A total of 276 patients (44.2\% female) receiving 1059 opioid co-prescriptions with other co-medications were identified during the study period. The mean age of all patients was $53.1 \pm 14.2$ years (mode 52; range 18-90 years; Table 2 ). Of the five age categories, patients aged between 51 and 65 years $(30.8 \%)$ were the predominant group, followed by those aged $66-80(27.9 \%), 41-50(18.5 \%),<40(18.5 \%)$ and $>80$ years $(4.4 \%)$.

Majority of patients were associated with cancer diagnoses (57.97\%; $n=160 / 276)$, while non-cancer diagnoses were associated with $42 \%(n=116 / 726)$ of patients. The common types of pain for non-cancer diagnoses include musculoskeletal pain $(10.51 \%)$, post-surgical and post-traumatic pain $(6.16 \%)$ and pain due to infection (5.07\%). Psychiatric disorders comprise $8.33 \%$ of patients (depressive disorders $5.07 \%$ and schizophrenia $3.26 \%$; Table 2).

Table 2 Patients characteristics

\begin{tabular}{|c|c|c|}
\hline Descriptions & $\mathbf{n}$ & $\%$ \\
\hline No of patients & 276 & \\
\hline \multicolumn{3}{|l|}{ Age, years } \\
\hline Mean & 53.1 & \\
\hline Median & 54 & \\
\hline Mode & 52 & \\
\hline Range & $18-90$ & \\
\hline Standard deviation & 14.2 & \\
\hline \multicolumn{3}{|l|}{ Age group, years } \\
\hline$<40$ & 51 & 18.48 \\
\hline $4 I-50$ & 51 & 18.48 \\
\hline $5 I-65$ & 85 & 30.8 \\
\hline $66-80$ & 77 & 27.9 \\
\hline$>80$ & 12 & 4.35 \\
\hline \multicolumn{3}{|l|}{ Gender } \\
\hline Female & 122 & 44.2 \\
\hline Male & 154 & 55.8 \\
\hline \multicolumn{3}{|l|}{ Diagnoses } \\
\hline Cancer diagnoses & 160 & 57.97 \\
\hline Non-cancer diagnoses & 116 & 42.03 \\
\hline \multicolumn{3}{|l|}{ Type of pain (non-cancer diagnoses) } \\
\hline Musculoskeletal pain & 29 & 10.51 \\
\hline Post-surgical and post-traumatic pain & 17 & 6.16 \\
\hline Infection & 14 & 5.07 \\
\hline Headache disorders & 6 & 2.17 \\
\hline Abdominal pain & 4 & 1.45 \\
\hline Cardiovascular system & 4 & 1.45 \\
\hline Fibromyalgia & 4 & 1.45 \\
\hline Trigeminal neuralgia & 4 & 1.45 \\
\hline Other miscellaneous & II & 3.99 \\
\hline \multicolumn{3}{|c|}{ Psychiatric disorders (non-cancer diagnoses) } \\
\hline Depressive disorders & 14 & 5.07 \\
\hline Schizophrenia & 9 & 3.26 \\
\hline
\end{tabular}

Majority of patients (90\%) were receiving a combination of opioid with one co-medication (combination 2) compared to a combination of opioid with two or more comedications (10\%; combination 3$)$. In combination 2 , the patients were most commonly co-prescribed with opioid + opioid (55.5\%) followed by opioid + anticonvulsant (16.9\%), opioid + benzodiazepine (9.3\%) and opioid + antidepressant (2.9\%). The co-prescriptions of opioid with antipsychotics and hypnotics accounted for $5.3 \%$. In combination 3, the patients were more frequently co-prescribed with opioid + benzodiazepine + antidepressant $(1.9 \%)$ followed by opioid + anticonvulsant + antidepressant (1.3\%) and opioid + benzodiazepine + anticonvulsant (1.0\%). Other co-prescriptions of opioid with two and three co-medications (others 3 and others $>3$ ) including antipsychotics and hypnotics accounted for $5.7 \%$ (Figure 1).

Overall, in both combination 2 and combination 3, the co-prescriptions of opioid with any combination involving benzodiazepine were issued to $12.3 \%$ of patients, opioid with anticonvulsant to $19.3 \%$ of patients, opioid with antidepressant to $6.3 \%$ of patients and other co-prescriptions to $10.9 \%$ of patients. The rest of the co-prescriptions involved opioid + opioid (55.5\% of patients).

\section{Number of co-prescriptions}

The proportion of number of co-prescriptions for each combination was similar to the number of patients reported earlier (Figure 2). Tramadol and alprazolam were the most commonly co-prescribed in the combination of opioid + benzodiazepine. In other combination 2 , the following drugs were the most frequently co-prescribed: morphine and oxycodone for opioid + opioid, oxycodone and gabapentin for opioid + anticonvulsant, oxycodone/morphine/fentanyl and amitriptyline for opioid + antidepressant and tramadol + zolpidem + haloperidol for others 2 combination (Table 1).

In the opioid + benzodiazepine combination, alprazolam was the most frequently used benzodiazepine followed by clonazepam, diazepam, midazolam and lorazepam. In this combination also, tramadol was the most commonly used opioid followed by oxycodone and morphine.

In the combination 3, tramadol, alprazolam and sertraline were the most commonly co-prescribed for opioid + benzodiazepine + antidepressant combination. The most frequently prescribed in other combination 3 were tramadol, gabapentin and amitriptyline for opioid + anticonvulsant + antidepressant, tramadol, alprazolam and sodium valproate for opioid + benzodiazepine + anticonvulsant, tramadol, zolpidem, olanzapine and alprazolam for others 3 combination and 


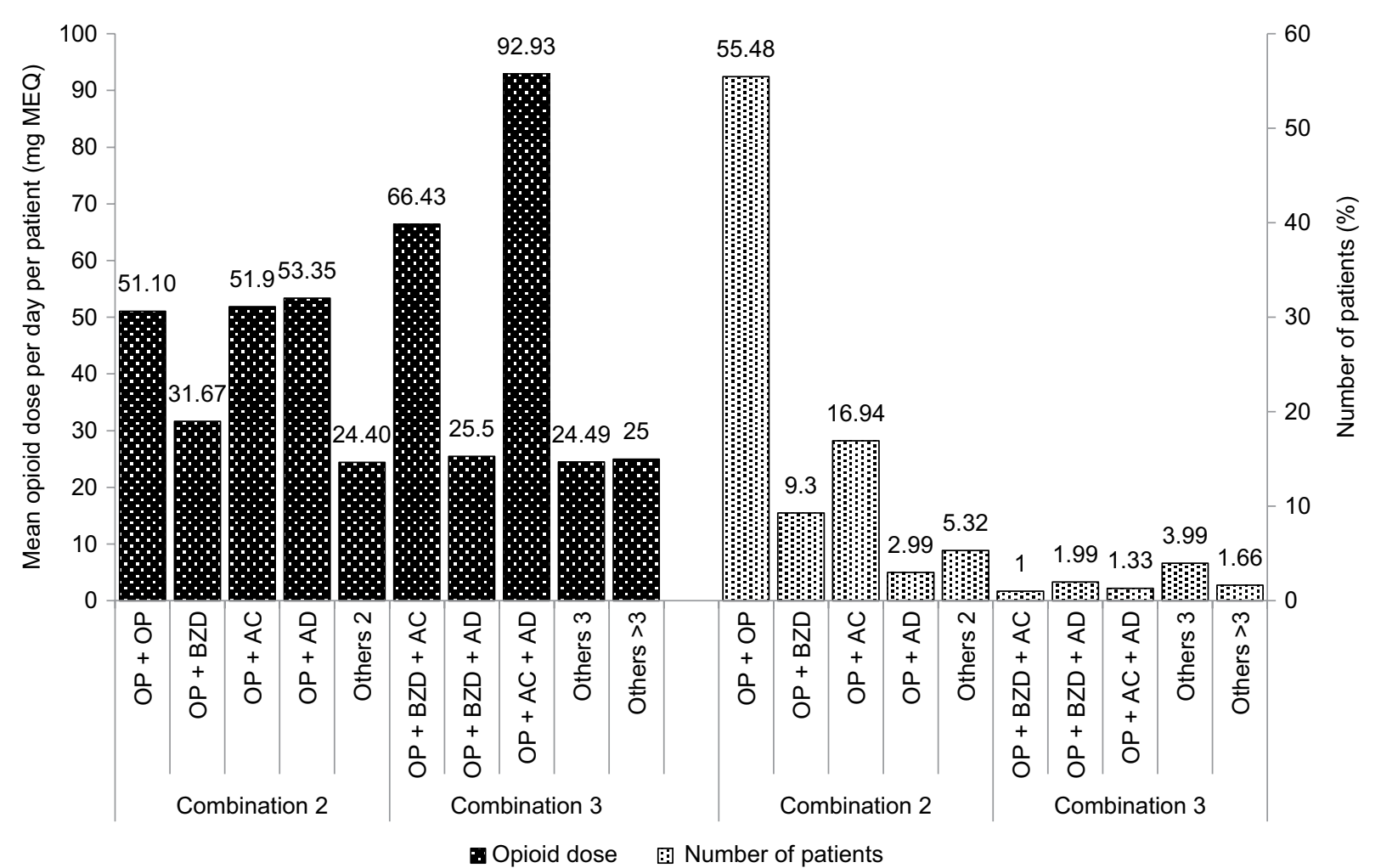

Figure I Mean OP dose per day per patient and number of patients in each combination.

Notes: Others $2=O P+$ hypnotics or OP + antipsychotic; others $3=O P+B Z D+$ hypnotics or OP + BZD + antipsychotics or OP + AC + hypnotics or OP + AD + hypnotics or $\mathrm{OP}+\mathrm{AC}+$ antipsychotics or $\mathrm{OP}+$ antipsychotics + hypnotics; others $>3=$ more than three drugs combination.

Abbreviations: OP, opioid; AC, anticonvulsant; BZD, benzodiazepine; AD, antidepressant.

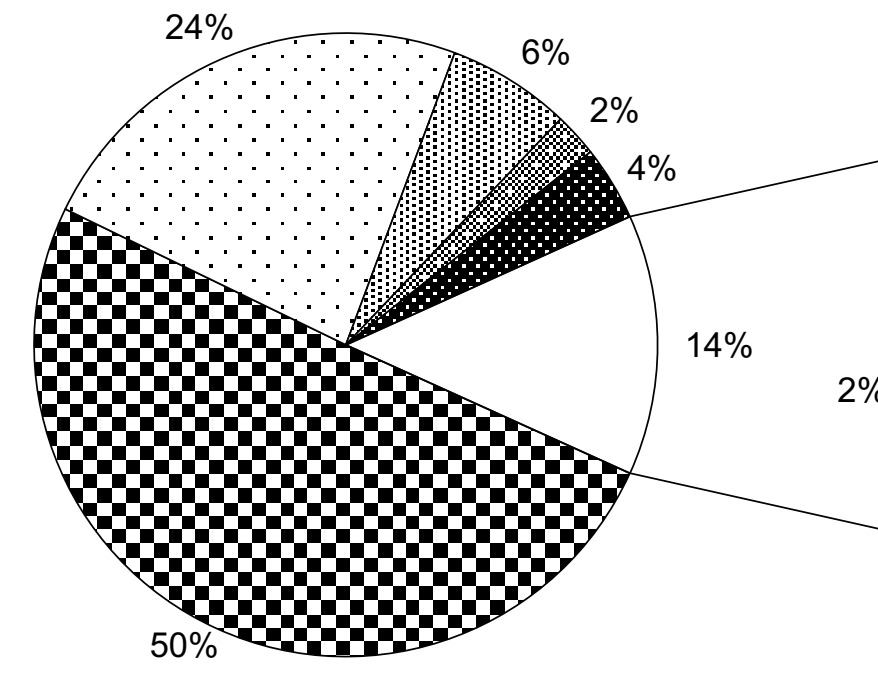

Combination 2

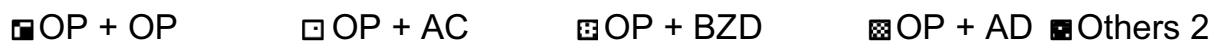

$$
\begin{aligned}
& \square \mathrm{OP}+\mathrm{BZD}+\mathrm{AD} \backsim \mathrm{OP}+\mathrm{AC}+\mathrm{AD} \square \mathrm{OP}+\mathrm{BZD}+\mathrm{AC} \text {-Others } 3 \boxminus \text { Others }>3
\end{aligned}
$$

Figure 2 Number of co-prescriptions for each combination.

Notes: Others 2 = OP + hypnotics or OP + antipsychotic; others $3=\mathrm{OP}+\mathrm{BZD}+$ hypnotics or OP + BZD + antipsychotics or OP + AC + hypnotics or OP + AD + hypnotics or OP + AC + antipsychotics or OP + antipsychotics + hypnotics; others $>3=$ more than three drugs combination.

Abbreviations: OP, opioid; AC, anticonvulsant; BZD, benzodiazepine; AD, antidepressant. 


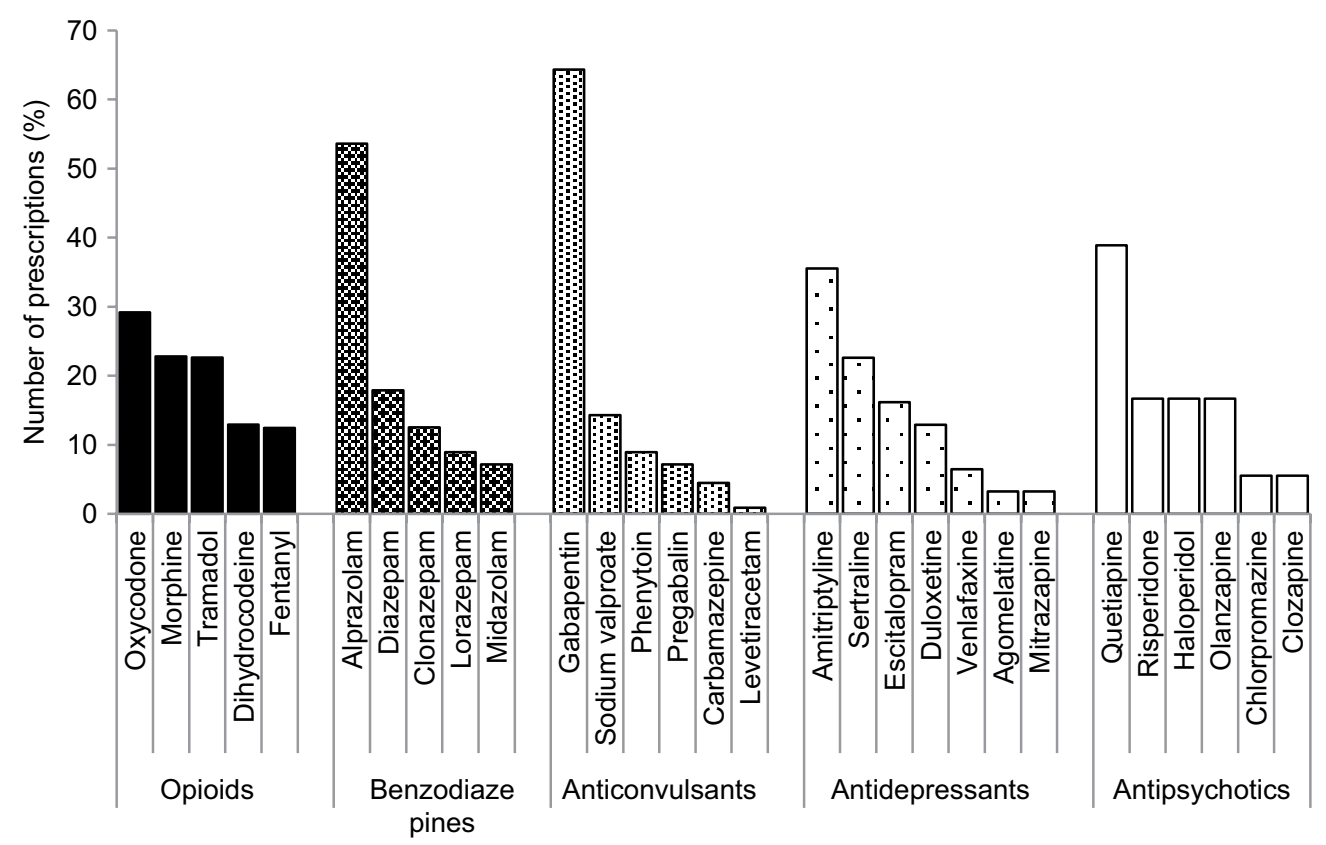

Figure 3 Number of prescriptions for each drug category.

Note: Hypnotics was not included in the graph as it has only zolpidem in the combination.

tramadol, alprazolam, quetiapine and sodium valproate for others $>3$ combination (Table 1).

Analysis on each drug category showed that oxycodone was the most frequently prescribed opioid (29.2\%), followed by morphine (22.8\%), tramadol (22.6\%), dihydrocodeine $(12.9 \%)$ and fentanyl (12.5\%). The majority of benzodiazepine prescriptions were for alprazolam (53.6\%), followed by diazepam (17.9\%), clonazepam (12.5\%), lorazepam (8.93\%) and midazolam (7.1\%). Gabapentin (64.3\%) was the predominant anticonvulsant compared to sodium valproate (14.3\%), phenytoin $(8.9 \%)$, pregabalin $(7.1 \%)$, carbamazepine $(4.5 \%)$ and levetiracetam $(0.9 \%)$. For antidepressants, amitriptyline (35.5\%) was the most commonly prescribed followed by sertraline (22.6\%), escitalopram (16.1\%), duloxetine (12.9\%), venlafaxine (6.5\%), agomelatine (3.2\%) and mirtazapine (3.2\%). For antipsychotics, quetiapine (38.9\%) was the most frequently prescribed followed by risperidone (16.7\%), haloperidol (16.7\%), olanzapine (16.7\%), chlorpromazine $(5.6 \%)$ and clozapine $(5.6 \%)$, and for hypnotics, zolpidem (100\%; Figure 3).

\section{Mean daily opioid dose}

The mean daily opioid dose per patient in the combination of opioid + anticonvulsant + antidepressant was the highest (92.9 mg morphine equivalents) followed by the combination of opioid + benzodiazepine + anticonvulsant $(66.4 \mathrm{mg})$, opioid + antidepressant (53.4 mg), opioid + anticonvulsant (51.9 mg), opioid + opioid (51.1 mg) and opioid + benzodiazepine $(31.67 \mathrm{mg})$. The mean daily dose per patient for other combinations was $<30 \mathrm{mg}$ morphine equivalents.

\section{Discussion}

Majority of opioid users in this study were prescribed with the combination of opioid with one co-medication in which opioid and anticonvulsant were the most frequently combined. The co-prescriptions of opioid with benzodiazepine were prescribed to $12.3 \%$ of patients. The findings from other studies reported that $18-44 \%$ of patients with chronic non-cancer pain were concurrently prescribed opioids with benzodiazepines. ${ }^{12,27,28} \mathrm{~A}$ study using a national database in Norway that was conducted in persistent opioid users reported that $60 \%$ of these patients were dispensed a benzodiazepine or benzodiazepine-related hypnotic, ${ }^{29}$ whereas a similar study using American prescription database reported a significantly lower prevalence of $30 \% .^{30}$

This study evaluated the co-prescriptions among opioid users at an outpatient tertiary hospital setting, making it difficult to compare the findings directly with those of other studies that evaluated the large population or a national level of opioid co-prescriptions using large health care databases. Nevertheless, the finding is inconsistent with the recent guidelines for the treatment of chronic pain, which recommended 
that the concurrent prescribing of opioid pain medication with benzodiazepines should be avoided whenever possible. ${ }^{10,31}$

The safety concerns were raised with the concurrent use of benzodiazepines with opioids because it may increase the risk of severe adverse events and problematic opioid use among opioid users including opioid overdose death. ${ }^{29,32,33}$ Previous research has shown that the presence of additional central nervous system-depressant drugs, which include benzodiazepine, was one of the contributing factors to the opioid overdose death apart from physician knowledge deficit, non-adherence to the prescribed medications and substance use disorders. ${ }^{34}$ It was also reported that the risk of overdose death was increased 15 -fold in patients filling both opioid and benzodiazepine prescriptions compared with those filling neither prescription. ${ }^{35}$ This alarming finding indicates that vigilance is required when opioids and benzodiazepines are co-prescribed to patients. It is important to identify and monitor patients who are at increased risk for adverse outcomes and to taper off the benzodiazepine. In view of this, it is also suggested for the health care providers to review the necessity of keeping benzodiazepines on board.

This study also found that tramadol and alprazolam were the most commonly combined in the co-prescription of opioid and benzodiazepine. The US national data collected from 2003 to 2009 identified oxycodone and alprazolam as the two prescription drugs with the greatest increases in associated death rates. ${ }^{17}$ In Malaysia, tramadol is categorized under prescription item and not included under the controlled drug category. ${ }^{36}$ If we consider the controlled drugs, this study indicated that oxycodone is the most commonly used together with alprazolam, which is in a similar pattern to the national data from the US. ${ }^{17}$ However, it is not possible for this study to compare the opioid use between the US and Malaysia because the data on opioid use in Malaysia are lacking particularly on the associated opioid death rates. Nevertheless, the consequence of the combination warrants further investigation.

This study has also shown that $6.3 \%$ of patients were receiving the co-prescriptions of opioid with antidepressants in which amitriptyline, sertraline and escitalopram were the most frequently used. This proportion was much lower than the results reported by other similar studies $(31-47 \%) .^{29,37}$ This may be partly explained by the co-medication with benzodiazepines in this study, which was slightly higher $(12.3 \%)$ making it less needed for antidepressants.

Although the design of this study does not allow determination of reasons for benzodiazepine initiation and whether it was used as the first-line or second-line drug, it is impor- tant to highlight that antidepressants are recommended for first-line therapy in neuropathic pain conditions. Apart from pain-relieving effect, antidepressants such as amitriptyline may be used for sleep and depression without having additive potential of benzodiazepines. Serotonin selective reuptake inhibitors (SSRIs) are the first-line therapy for depression and panic anxiety, while benzodiazepine is the second-line therapy with limitation to short-term therapy for patients who are unable to tolerate the first-line therapy. ${ }^{38}$

Almost $20 \%$ of opioid users from this study were receiving co-prescriptions of opioids with anticonvulsants most probably for the treatment of neuropathic pain. This finding supports the previous research that reported the prevalence for concomitant use of opioid with anticonvulsants (20 $34 \%) .{ }^{29,37}$ Anticonvulsants such as gabapentin and pregabalin have established efficacy and generally good safety profile in neuropathic pain conditions. Thus, they are recommended as the first-line therapy for these conditions, and the usage should be encouraged. ${ }^{3}$

This study has also observed that other co-medications that include antipsychotics and hypnotic were prescribed to $10 \%$ of opioid users. Quetiapine, risperidone, olanzapine and haloperidol were among the commonly used antipsychotics. These drugs were likely used in the treatment of psychiatric comorbidities in which $3.1 \%$ of patients in this study were associated with schizophrenia. Antipsychotics might also be used as an add-on therapy in the treatment of painful conditions, but the evidence to support the usage is lacking. The side effects such as extrapyramidal, sedation and drug interactions, particularly in older patients, need to be considered. ${ }^{5}$

With regard to opioid dose, this study showed that the mean opioid dose in all types of co-prescriptions was within the recommended dose of $<100 \mathrm{mg} / \mathrm{d}$ morphine equivalents. The highest opioid dose was in the combination of opioid + anticonvulsant + antidepressant (92.9 mg morphine equivalents). For the co-prescriptions involving opioids + benzodiazepines, the opioid doses were moderate ranging from 31 to $66 \mathrm{mg}$ morphine equivalents per day. Previous research reported that benzodiazepines were commonly prescribed to opioid users who received high doses of opioids. ${ }^{14,32}$ The findings were different from this study, which may be explained by the various study population and the varying methods used in calculating the opioid dose in the previous research.

The overall findings on the use of co-medications in this study reflect the prevalence of comorbidities and more severe pain among opioid users, and this biopsychosocial issue of chronic pain requires comprehensive approaches involving multidisciplinary pain management team. The strength of 
this study is that it adds to a nascent understanding of the practice of opioid co-prescribing with benzodiazepine and other co-medications among opioid users with the details of opioid doses in each co-prescription at an outpatient hospital setting in Malaysia. This study indicates real practice and it is not associated with recall bias. Several limitations of this study should be noted such as the findings may not be generalized to an inpatient setting as it was conducted at an outpatient setting. This study is retrospective and cross-sectional in nature in that it employs data from opioid prescription records that have limited information on the treatment outcomes such as pain reduction, quality of life or adverse events. It might be worthwhile for patients to use the co-medications particularly with benzodiazepine if they obtained adequate pain relief and accept the risks in order to secure a good quality of life, but this cannot be answered in this study because the patients were not asked about their experience. The diagnoses identified from the prescriptions also lacked details on frequency, severity and duration of symptoms. Pharmacy records used in this study represent dispensed opioids and other co-medications and may not reflect actual use or whether the medications were used as prescribed. However, the validity of data on drugs that have actually been dispensed to patients is probably higher than the data from the prescriptions in physicians' record. ${ }^{39}$

\section{Conclusion}

This study demonstrated that among opioid users receiving concomitant medications at a tertiary hospital setting in Malaysia, the co-prescriptions of opioid with benzodiazepine were prescribed to $12.3 \%$ of patients in which tramadol and alprazolam were the most commonly combined and its individual opioid dose was moderate. Other co-medications with antidepressants, anticonvulsants and antipsychotics were also common and the opioid dose in all types of coprescriptions was within the recommended dose. In view of safety concerns with certain co-prescriptions, those who were using opioids with benzodiazepines appear to represent a particularly high-risk group. Future studies are warranted to evaluate the adverse effects and clinical outcomes of this co-prescription particularly in long-term opioid users with chronic non-cancer pain.

\section{Acknowledgments}

CSZ was supported by research grants from The International Islamic University Malaysia (Endowment B-EDW 14-0950980) and The Ministry of Education Malaysia (Fundamental Research Grant Scheme-FRGS 14-195-0436).

\section{Author contributions}

CSZ initiated and developed the research questions and study design, conducted data management and analysis and drafted the manuscript. All the authors contributed to the data acquisition and interpretation of the data, critically revised the manuscript and approved the final version submitted for publication.

\section{Disclosure}

The authors report no conflicts of interest in this work.

\section{References}

1. Sullivan MD, Edlund MJ, Lily Z, Jurgen U, Wells KB. Association between mental health disorders, problem drug use, and regular prescription opioid use. Arch Intern Med. 2006;166(19):2087-2093.

2. Fishbain DA. Polypharmacy treatment approaches to the psychiatric and somatic comorbidities found in patients with chronic pain. Am J Phys Med Rehabil. 2005;84(3):S56-S63.

3. Attal N, Bouhassira D. Pharmacotherapy of neuropathic pain: which drugs, which treatment algorithms. Pain. 2015;156(suppl):S104-S114.

4. Ministry of Health Malaysia [homepage on the Internet]. Clinical Practice Guidelines: Management of Major Depressive Disorder, Ministry of Health Malaysia; 2007. Available from: http://www.acadmed.org. my/. Accessed January 10, 2017

5. Seidel S, Aigner M, Ossege M, Pernicka E, Wildner B, Sycha T. Antipsychotics for acute and chronic pain in adults. Cochrane Database Syst Rev. 2013;8(1):CD004844.

6. Reddy S, Patt RB. The benzodiazepines as adjuvant analgesics. $J$ Pain Symptom Manage. 1994;9(8):510-514.

7. Giummarra MJ, Hons BA, Gibson SJ, et al. Polypharmacy and chronic pain : harm exposure is not all about the opioids. Pain Med. 2015;16: 472-479.

8. Calcaterra S, Glanz J, Binswanger IA. National trends in pharmaceutical opioid related overdose deaths compared to other substance related overdose deaths: 1999-2009. Drug Alcohol Depend. 2013;131(3):263-270.

9. Chretien KC, Azar J, Kind T. Pharmaceutical overdose deaths, United States 2010. Am Med Assoc. 2011;305(6):566-568.

10. Manchikanti L, Abdi S, Atluri S, et al. American Society of Interventional Pain Physicians (ASIPP) guidelines for responsible opioid prescribing in chronic non-cancer pain: part 2 - guidance. Pain Physician. 2012;15(S67_S116):67-116.

11. Webster LR, Choi Y, Desai H, Webster L, Grant BJB. Sleep-disordered breathing and chronic opioid therapy. Pain Med. 2008;9(4): 425-432.

12. Kouyanou K, Pither C, Wessely S. Medication misuse, abuse and dependence in chronic pain patients. $J$ Psychosom Res. 1997;43(5): 497-504.

13. Morasco BJ, Duckart JP, Carr TP, Deyo RA, Dobscha SK. Clinical characteristics of veterans prescribed high doses of opioid medications for chronic non-cancer pain. Pain. 2010;151(3):625-632.

14. Saunders K, Von Korff M, Campbell CI, et al. Concurrent use of alcohol and sedatives among persons prescribed chronic opioid therapy: prevalence and risk factors. J Pain. 2013;13(3):266-275.

15. Miller M, Barber CW, Leatherman S, et al. Prescription opioid duration of action and the risk of unintentional overdose among patients receiving opioid therapy. JAMA Intern Med. 2015;175(4):608-615.

16. Deyo RA, Smith DHM, Johnson ES, et al. Opioids for back pain patients: primary care prescribing patterns and use of services. J Am Board Fam Med. 2013;24(6):717-727.

17. Jann M, Kennedy WK, Lopez G. Benzodiazepines: a major component in unintentional prescription drug overdoses with opioid analgesics. J Pharm Pract. 2014;27(1):5-16. 
18. Park TW, Saitz R, Ganoczy D, Ilgen MA, Bohnert AB. Benzodiazepine prescribing patterns and deaths from drug overdose among US veterans receiving opioid analgesics: case-cohort study. BMJ. 2015; 350:h2698.

19. Zin CS, Chen LC, Knaggs RD. Changes in trends and pattern of strong opioid prescribing in primary care. Eur J Pain. 2014;18(9):1343-1351.

20. Sullivan MD, Edlund MJ, Fan MY, DeVries A, Brennan BJ, Martin BC. Trends in use of opioids for non-cancer pain conditions 2000-2005 in Commercial and Medicaid insurance plans: The TROUP study. Pain. 2008;138(2):440-449.

21. Svendsen K, Borchgrevink P, Fredheim O, Hamunen K, Mellbye A, Dale O. Choosing the unit of measurement counts: the use of oral morphine equivalents in studies of opioid consumption is a useful addition to defined daily doses. Palliat Med. 2011;25(7):725-732.

22. Von Korff M, Saunders K, Thomas Ray G, et al. De facto long term opioid therapy for noncancer pain. Clin J Pain. 2008;24:521-527.

23. Sullivan MD, Bauer AM, Fulton-Kehoe D, et al. Trends in opioid dosing among Washington State Medicaid patients before and after opioid dosing guideline implementation. J Pain. 2016;17(5):561-568.

24. Braden JB, Fan MY, Edlund MJ, Martin BC, DeVries A, Sullivan MD. Trends in use of opioids by noncancer pain type 2000-2005 among Arkansas Medicaid and Health Core Enrollees: results from the TROUP study. J Pain. 2008;9(11):1026-1035.

25. Edlund MJ, Martin BC, Devries A, Fan M, Braden JB, Sullivan MD. Trends in use of opioids for chronic non-cancer pain among individuals with mental health and substance use disorders: the TROUP study. Clin J Pain. 2010;26(1):1-8.

26. Edlund MJ, Austen MA, Sullivan MD, et al. Patterns of opioid use for chronic noncancer pain in the Veterans Health Administration from 2009 to 2011. Pain. 2014;155(2014):2337-2343.

27. Manchikanti L, Cash KA, Malla Y, Pampati V, Fellows B. A prospective evaluation of psychotherapeutic and illicit drug use in patients presenting with chronic pain at the time of initial evaluation. Pain Physician. 2013;16(1):E1-E13.
28. King S, Strain J. Benzodiazepine use by chronic pain patients. Clin J Pain. 1990;6:143-147.

29. Mellbye A, Svendsen K, Borchgrevink PC, Skurtveit S, Fredheim OMS. Concomitant medication among persistent opioid users with chronic non-malignant pain. Acta Anaesthesiol Scand. 2012;56(10):1267-1276.

30. Boudreau D, Von Korff M, Rutter CM, et al. Trends in long-term opioid therapy for chronic non-cancer pain. Pharmacoepidemiol Drug Saf. 2009;18(12):1166-1175.

31. Dowell D, Haegerich TM, Chou R. CDC guideline for prescribing opioids for chronic pain - United States, 2016. JAMA. 2016;315(15): $1624-1645$.

32. Nielsen S, Lintzeris N, Bruno R, et al. Benzodiazepine use among chronic pain patients prescribed opioids: associations with pain, physical and mental health, and health service utilization. Pain Med. 2015;16(2):356-366.

33. Hawkins EJ, Malte CA, Saxon AJ. Prevalence and trends of concurrent opioid analgesic and benzodiazepine use among veterans affairs patients with post-traumatic stress disorder, 2003 - 2011. Pain Med. 2015; 16(10):1943-1954.

34. Webster LR, Cochella S, Dasgupta N, et al. An analysis of the root causes for opioid-related overdose deaths in the United States. Pain Med. 2011;12(suppl 2):S26-S35.

35. Peirce GL, Smith MJ, Abate MA, Halverson J. Doctor and pharmacy shopping for controlled substances. Med Care. 2012;50(6):494-500.

36. Biro Pharmaceutical Malaysia. Poisons List; 2016. Available from http:/www.pharmacy.gov.my/v2/sites/default/files/document-upload/ poisons-list-appendix-3-aug-2016_4.pdf. Accessed January 10, 2017.

37. Parsells KJ, Cook SF, Kaufman DW, Anderson T, Rosenberg L, MitchellAA Prevalence and characteristics of opioid use in the US adult population. Pain. 2008;138(3):507-513.

38. Dellemijn PL, Fields HL. Do benzodiazepines have a role in chronic pain management. Pain. 1994;57(2):137-152.

39. Fredheim OM. Increasing use of opioids for pain. Eur J Pain. 2014;18(9): 1219-1220.
Journal of Pain Research

\section{Publish your work in this journal}

The Journal of Pain Research is an international, peer reviewed, open access, online journal that welcomes laboratory and clinical findings in the fields of pain research and the prevention and management of pain. Original research, reviews, symposium reports, hypothesis formation and commentaries are all considered for publication.

\section{Dovepress}

The manuscript management system is completely online and includes a very quick and fair peer-review system, which is all easy to use. Visit http://www.dovepress.com/testimonials.php to read real quotes from published authors. 